\title{
HIV Seroprevalence in Patients Undergoing Ophthalmic Surgery in the Niger/Delta Region of Nigeria
}

\author{
V Odogu FRCS, ${ }^{1}$ K Mercieca MD ${ }^{2}$ R Thampy MBChB, MSc, ${ }^{1}$ B Fiebai FMCOphth ${ }^{3}$ \\ ${ }^{1}$ Department of Ophthalmology, Royal Oldham Hospital, Oldham, UK \\ ${ }^{2}$ Manchester Royal Eye Hospital, UK \\ ${ }^{3}$ Department of Ophthalmology, University of Port Harcourt Teaching Hospital, Port-Harcourt, Nigeria
}

\section{SUMMARY}

Aim: The aim of this study was to determine the number of HIV positive cases undergoing ophthalmic surgery at two centres in Nigeria and to assess if routine testing is clinically or economically effective.

Methods: All patients listed for ophthalmic surgery in two eye units in southern Nigeria during a six-month period in 2005, who underwent a routine set of pre-operative blood tests including HIV test-after giving full-informed consent, were included. Laboratory investigation of HIV status was by ELISA. Details of the patients' age, sex, diagnosis and preoperative HIV status were noted on a spreadsheet database.

Results: At the university teaching hospital, HIV was detected in one out of 87 cases $(1.15 \%)$. At the other provincial hospital 3 HIV positive cases were detected out of 41 ophthalmic surgery patients $(7.31 \%)$.

Conclusion: The prevalence of HIV in Nigeria is high, although it varies between type of hospital and region. Ophthalmic surgeons should bear this in mind whilst operating. Routine testing of HIV status might not be absolutely necessary as it does not influence changes in surgical technique or preparation but rather reinforces the need for safe and effective preventive measures.

Key words: human immunodeficiency virus (HIV), seroprevalence, ophthalmic surgery, sub-Saharan Africa

\section{INTRODUCTION}

HIV infection rates in sub-Saharan Africa are particularly high. ${ }^{1}$ In Nigeria the prevalence of HIV in adults has a mean average of $3.9 \%(2.3 \%-5.6 \%)$ in a population of 140 million people. ${ }^{1}$ General surgeons are considered to be at occupational risk of transmission of the virus from patients. Strategies for reducing the risk of peri-operative HIV transmission include infection-control precautions and modifications of surgical technique. Where a patient is known to be HIV positive, steps taken to reduce the risk of peri-operative exposure include the use of disposable instruments, avoidance of blood spillage, double gloving and the use of waterproof gowns.

Mandatory pre-operative HIV testing is undertaken in many developing countries. In Nigeria, some surgical units follow general surgical guidelines by routinely checking the HIV status of all patients at the time of pre-operative assessment. The process is time-consuming and adds to the cost of the procedure.

\section{A IM}

This study was carried out to determine the prevalence of HIV positive cases amongst patients undergoing ophthalmic surgery in two eye centres in Nigeria and to assess if routine testing is clinically or economically effective.

The general aim of the study is to examine the rate of HIV positive ophthalmic patients against a background of high HIV prevalence in the population and thus consider the arguments for risk-stratified screening for HIV and the methods of reducing transmission of infection to surgeons.

\section{METHODS}

All patients listed for elective ophthalmic surgery in two eye units in southern Nigeria during a six-month period in 2005 were included in the study. Each patient underwent a routine set of pre-operative blood tests - including HIV testing - after giving full informed consent. Laboratory investigation of HIV status was done by Enzyme Linked Immunosorbent Assay (ELISA). Where a positive result was noted two further confirmatory tests were carried out in accordance with WHO guidelines ${ }^{2}$. Patients with indeterminate samples were retested nine weeks later. Details of the patients' age , sex, diagnosis and preoperative HIV status were entered into an anonymous spreadsheet database.

${ }^{*}$ Correspondence: Dr B Fiebai, Department of Ophthalmology, University of Port Harcourt Teaching Hospital, Rivers State, Nigeria Email: bassief@yahoo.com 


\section{RESULTS}

At the University Teaching Hospital, Port Harcourt, HIV was detected in 1 out of 87 cases $(1.1 \%$ confidence interval $0.03 \%$ to $6.2 \%$ ). At the provincial Okolobiri General Hospital, HIV was detected in 3 out of 41 ophthalmic surgery patients (7.3\%, confidence interval $1.5 \%$ to $19.9 \%$ ). Total HIV prevalence in the study was 4/128 (3.0\%) See tables 1 and 2.

Table 1. Distribution of patients by ophthalmic diagnosis and location

\begin{tabular}{|c|c|c|}
\hline & \multicolumn{2}{|c|}{ University Teaching Hospital } \\
\hline & Negative & Positive \\
\hline Cataract & 50 & 1 \\
\hline Corneal & 10 & 0 \\
\hline Lid surgery & 6 & 0 \\
\hline Trauma & 11 & 0 \\
\hline Unknown & 5 & 0 \\
\hline \multirow[t]{3}{*}{ Others } & 4 & 0 \\
\hline & \multicolumn{2}{|c|}{ Provincial General Hospital } \\
\hline & Negative & Positive \\
\hline Cataract & 38 & 3 \\
\hline \multicolumn{3}{|c|}{ University Teaching Hospital } \\
\hline \multicolumn{3}{|c|}{ HIV prevalence $1.1 \%$} \\
\hline \multicolumn{3}{|c|}{ Age: mean $=47.0$, standard deviation 24.5} \\
\hline \multicolumn{3}{|c|}{ Sex: male $40(46 \%)$ female $47(54 \%)$} \\
\hline \multicolumn{3}{|c|}{ Provincial General Hospital } \\
\hline \multicolumn{3}{|c|}{ HIV prevalence $7.31 \%$} \\
\hline \multicolumn{3}{|c|}{ Age: mean $=48.6$, standard deviation $=19.9$} \\
\hline Sex: male 21 & $8(46 \%)$ & \\
\hline
\end{tabular}

Table 2. Prevalence, age and sex distribution of HIV/AIDS amongst patients undergoing ophthalmic surgery in Nigeria

\begin{tabular}{lcc}
\hline & UPTH & OKOLOBIRI \\
\hline HIV prevalence $(\%) *$ & 1.1 & 7.3 \\
Age-mean (SD) & $47.0(24.5)$ & $48.6(19.9)$ \\
Sex $n(\%)$ & $40(46)$ & $21(54)$ \\
Male & $47(54)$ & $18(46)$ \\
Female & & \\
* Fisher exact test $=\mathrm{p}=0.1$ &
\end{tabular}

\section{DISCUSSION}

HIV infection rates in sub-Saharan Africa are particularly high although large variations exist between individual countries.
Prevalence varies from $1 \%$ in countries like Somalia and Senegal to $15-20 \%$ in South Africa and Zambia. In four southern African countries, the national adult HIV prevalence rate has risen higher than was thought possible and now exceeds $20 \%$. These countries are Botswana (24.1\%), Lesotho (23.2\%), Swaziland (33.4\%) and Zimbabwe (20.1\%). ${ }^{1}$

Nigeria is the most populous country in sub-Saharan Africa with a population of 140 million people. Until recently the national prevalence rate of HIV has remained relatively low but it has grown slowly from below 2\% in 1993 to $3.9 \%$ in 2005. However, HIV infection rates in some states in Nigeria are as high as that of Cameroon (5.4\%). ${ }^{1}$ In total, around 2.9 million Nigerians are estimated to be living with HIV. ${ }^{1}$

This rising rate of HIV infection puts surgeons in Nigeria at a higher risk of occupationally acquired infection. Some surgeons in Nigeria, including ophthalmic surgeons, routinely test all surgical patients for HIV, but the majority are not aware of the CDC guidelines on universal precautions for blood-borne pathogens; up to $75 \%$ work in centres with no policies on parenteral exposure to blood and body fluids. ${ }^{3}$ Adequate protocols and facilities for prophylaxis for exposed health care workers are lacking and still need to be established, even for general surgeons. ${ }^{4}$

HIV seroprevalence rates in the study vary significantly between the two centers (table 2). The explanation lies in the demographic profile of patients, particularly age and financial capacity. Statistically, however, both rates fall within the confidence intervals of the official HIV prevalence in Nigeria.

The routine screening for HIV in pre-operative patients has gained popularity in various countries and hospital settings, including countries where HIV prevalence is not particularly high. ${ }^{5}$ Arguments in favour are that voluntary testing alerts the surgeon to higher risk patients and enables the incorporation of precautionary measures to minimize occupational risk of exposure. ${ }^{6}$

Risk of exposure and transmission varies according to procedure. The risk is highest with long procedures, and when blood loss is common, particularly in vascular, intraabdominal and gynaecological surgery.

Ophthalmic surgery is different from other surgical specialties in that exposure to blood is very limited in most procedures. One can therefore argue that routine HIV testing in all ophthalmic patients is expensive and unnecessary.

The International Centre for Eye Health (ICEH) states that during clinic procedures the risk of getting HIV from seropositive patients is probably very low. Unless the eye care worker has open wounds or dermatological lesions on his or her hands, no gloves need to be worn when examining HIV-seropositive patients. ${ }^{\text {? }}$ 
HIV has been isolated from ocular tissues but in small amounts, so that no special precautions need be taken when performing ophthalmic surgery, including cataract, on HIVseropositive patients. Going by the study results, this would mean that at least $81 \%$ of procedures could have been performed without prior HIV screening.

Operating gloves should always be worn, but the use of double gloving, although recommended as a precaution against puncture injuries in general surgery, is of uncertain value in most ophthalmic procedures. It might be sensible to take this precaution when performing procedures which involve more exposure to blood, cutting (e.g., exenteration) or drilling bony fragments (e.g., dacryocystorhinostomy). ${ }^{7}$

Corneal transplantation is a possible route of viral transmission, especially for viruses that infect the central nervous system. For this reason potential donors are discarded if the cause of death is as a result of viral infection or an unknown disease of the central nervous system.

The problem in a developing country like Nigeria is that eye bank facilities are nonexistent and donor corneas are often used within hours after enucleation, not allowing enough time for routine testing of the donor serum. Rapid serological ELISA tests could rule out HIV infection in the donor in such circumstances.

\section{CONCLUSION}

This study shows that although HIV prevalence may vary between type of hospital and region located, it remains high in Nigeria. A high prevalence of HIV-positive patients may be encountered in an operative setting. Ophthalmic surgeons should bear this in mind whilst operating. Although the routine testing of HIV status may not be necessary since its outcome does not influence changes in patient preparation or the surgical technique but rather re-enforces the need for safe and effective standard precautions. Further studies are needed to evaluate the differences between different centres and the feasibility of selective HIV screening.

\section{REFERENCES}

1. UNAIDS (2006), Report on the Global AIDS epidemic 2006, Annex 2: HIV / AIDS estimates and data, 2005.

2. Revised Guidelines for HIV Counseling, Testing, and Referral. Morbidity and Mortality Weekly Report, Centers for Disease Control and Prevention. Recommendations and Reports, November 9, 2001 / 50(RR19):1-58.

3. Adebamowo CA, Ezeome ER, Ajuwon JA, Ogundiran TO. Survey of the knowledge, attitude, and practice of Nigerian surgery trainees to HIV-infected persons and AIDS patients. BMC Surg 2002; 1: 7.

4. Eke N, Jamabo RS, Adotey JM, Jebbin NJ. HIV positive patients and the surgeon. Niger J Med 2004; 13(4): 366-71.

5. Kanno Y, Ogino H. A case of proven HIV infection upon emergency surgery for finger injury. Plast Reconstr Surg 2003; 46(2): 193-199.

6. LaPort DM, Mont MA, Jones LC, Padden DA, Hungerford DS. Human immunodeficiency virus testing for elective orthopaedic procedures: Results in a community based hospital. Orthopedics 2001; 24(1): 5255.

7. HIV / AIDS and the Eye. (homepage on the internet). (Updated 2001; cited 2006 November 17).Available from http:// www.cehjournal.org/files/tsno8/no08.pdf 